\title{
Equity Price Dynamics Before and After the Introduction of the Euro: A Note*
}

\author{
Yin-Wong Cheung \\ University of California, U.S.A. \\ Frank Westermann \\ University of Munich, Germany
}

Daily data from the German and U.S. equity markets before and after the introduction of the Euro are used to study the effect of exchange rate regime choices on equity markets. It is found that, since the introduction of the Euro, the volatility and the persistence of the German stock index have fallen significantly relative to those of the U.S. index. However, the switch in exchange rate arrangement appears to have no significant implication for the causal relationships - both the mean and variance causalities between the two equity markets (JEL G15).

\section{Introduction}

The choice of an exchange rate regime can significantly affect the behavior of economic variables and the shock transmission mechanism. However, the economic consequence of adopting a specific exchange rate policy is still an unsettled issue. For instance, Frankel and Mussa (1980) and Flood and Rose (1995) argue that fixing exchange rates will increase the volatility of economic fundamentals. On the other hand, Marston (1985) shows that the economic performance under different exchange rate arrangements depends on, for instance, the relative magnitudes of demand and supply shocks and of domestic and foreign shocks. Other studies on the implications of exchange rate regimes for the variability of economic variables include Artis and Taylor (1994), Baxter and Stockman (1989), and Rose (1995). ${ }^{1}$

1. Melvin (1985) and Berger et al. (2000) argue that the exchange rate regime is chosen endogenously and thus output variances in the home and foreign countries are robust 
The recent introduction of the Euro offers a unique opportunity to investigate the effects of exchange rate regimes. In this paper, we examine whether the launch of the single European currency has any observable implications for the German stock market. The existing studies provide limited evidence on the interaction between exchange rate policy and equity market volatility. Krugman and Miller (1993) suggest that, under a fixed rate regime, the volatility in equity markets goes down due to the reduction in the number of noise traders. In the case of the Euro, the dollar value of the single European currency in 1999 displayed a much smaller variability than that of the Deutsche Mark in, say, $1998 .^{2}$ The decline in exchange rate uncertainty can reduce the pricing uncertainty for German firms with overseas operations and for foreign investors. Thus, adopting the Euro can lower the German market volatility.

In a recent study, Bodart and Reding (1999) show that, under the different stages of the European Monetary System, an increase of exchange rate volatility was associated with a decline in the correlation of national bond markets and an exchange rate peg was associated with a reduction of bond price volatility. However, these authors found only weak evidence on the interaction between exchange rate regime and equity market behavior.

In this study, we compare and contrast the dynamic behavior of the German DAX index before and after the introduction of the Euro. Since the observed change in the German index may be due to the exchange rate policy or to some common development in the global equity market, we use the U.S. Dow Jones Industrial (hereafter, DJI for short) average as a control to see if the changes in the DAX index are unique to the German market. The use of the DJI index as a benchmark sharpens the interpretation of the subsequent empirical analysis. However, it should be noted that, similar to other studies on effects of the exchange rate regime choice, there may be other factors that affect the dynamics of the DAX index before and after the advent of the Euro. In our empirical

predictors of the exchange rate regime choice.

2. As noted by one referee, the advent of the Euro can increase or decrease the exchange rate uncertainty that German firms face. However, for the sample (which excludes the observations around January 1, 1999) examined in this exercise, the Euro exchange rate is less volatilte than the pre-1999 Deutsche Mark. 
analysis, we also study the interactions between the German and U.S. indexes before and after the introduction of the Euro.

In the next section, we present some preliminary analyses of the two stock indexes. In section III, GARCH models are used to study the dynamic properties of the stock indexes. The interactions between the two indexes are examined in section IV. Section V offers some concluding remarks.

\section{Preliminary Analysis}

Daily closing observations of the German DAX and the U.S. DJI indexes are used. Arguably, the DJI index is the best known U.S. stock index. It contains 30 large capitalization stocks that trade on the New York Stock Exchange and is usually viewed as a performance barometer of the largest stocks in the U.S. market. The DAX index, in the present form, was introduced on July 1, 1988. The index includes 30 German stocks, which have the highest turnover volume and market capitalization among stocks traded in the Frankfurt Stock Exchange (Deutsche Börse AG). The DAX index can be considered as the German counterpart of the DJI index. Both indexes represent more than one half of the total market capitalization in their respective exchanges. The sample period ranges from January 2, 1998 to December 29, 1999. A five-day window around January 1, 1999, the day the Euro was introduced, is excluded from the analysis. Following the convention in the literature, data are expressed in logs.

The two index series are graphed in figure 1. In 1998, the patterns of movement in the two indexes are quite similar. Both markets topped around the mid-1998, experienced a setback in the third quarter, and rallied in the last quarter of the year. The 1999 patterns are, on the other hand, quite different. The DJI index advanced faster in the first half of the year while the DAX index enjoyed a steeper increase in last quarter of the year.

The augmented Dickey and Fuller (ADF) test allowing for both an intercept and a time trend is employed to determine whether there is a unit root in the data series. Let $X_{i, t}$ be the stock price index of country 

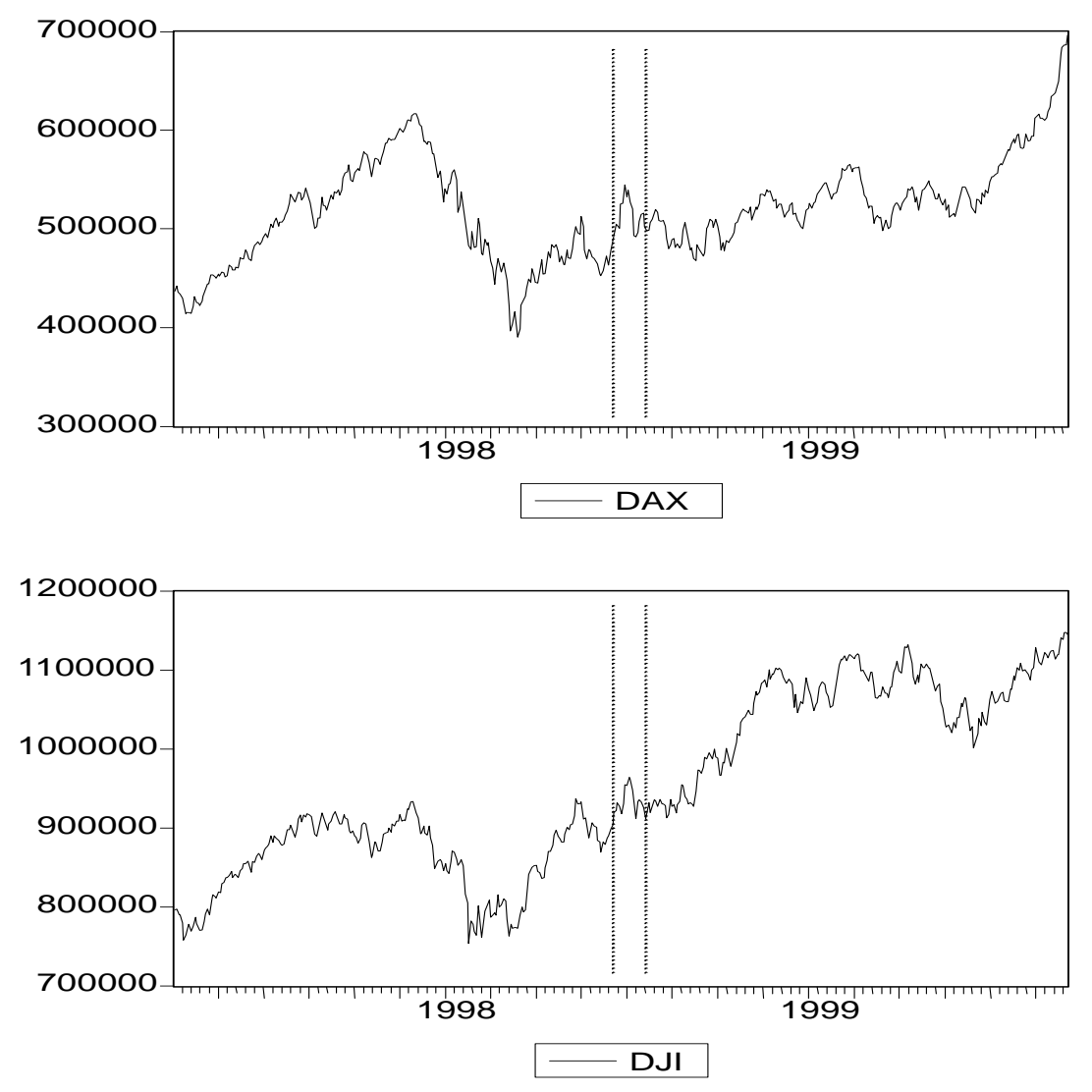

FIGURE 1.-The DAX and DJI indexes in log levels, $1 / 2 / 1998$ to 12/30/1999

$I$ ( $i=\mathrm{DAX}$ index, DJI index) at time $t$. The ADF test is based on the regression equation:

$$
\Delta X_{i, t}=\mu_{0}+\mu_{1} t+\alpha X_{i, t-1}+\ldots+\beta_{p} \Delta X_{i, t-p}+\varepsilon_{t},
$$

where $\Delta$ is the first-difference operator and $\varepsilon_{t}$ is an error term. The Akaike information criterion is used to determine $p$, the lag parameter. Results of applying the ADF test to the data and their first differences are shown in table 1 . For each individual stock series, the unit root null hypothesis is not rejected. The same hypothesis is, however, rejected for 
TABLE 1. Unit Root Test Results

\begin{tabular}{|c|c|c|c|c|}
\hline & \multicolumn{2}{|c|}{ Levels } & \multicolumn{2}{|c|}{ First Difference } \\
\hline & 1998 & 1999 & 1998 & 1999 \\
\hline DAX & -1.68 & 1.23 & $-6.36^{*}$ & $-8.29 *$ \\
\hline DJI & -1.86 & -1.73 & $-7.08 *$ & $-8.14 *$ \\
\hline
\end{tabular}

Note: The ADF test statistics calculated from the levels and first differences of the DAX and DJI indexes in logs are reported. The lag parameters are set to one, as chosen by the Akaike information criterion. "*" indicates significance at the five percent level. Significance of the statistics is evaluated using the Cheung and Lai (1995) finite sample critical values ( -3.43 for the case of levels and -2.87 for the case of first differences). The unit root hypothesis is not rejected for the data series but is rejected for their first differences.

the first-differenced data. Thus, there is one unit root in each of the two equity indexes, a result that is consistent with the literature. In the subsequent analysis, we assume the data are $I(1)$; that is, difference stationary.

Figure 2 depicts two index return series (first log differences). For both the 1998 and 1999 sample periods, the DAX index appears more volatile than the DJI index. For each return series, the volatility in the 1998 period seems to be higher than that in the 1999 period. Both the standard error and range statistics in table 2 confirm that the DAX index return series is more variable than the DJI index. According to the sample statistics, the two return series experience a reduction in variability across the two sample years. However, the standard error suggests the DAX return series has a bigger decline in variability while the range statistic shows a steeper decline for the DJI return series. The sample correlation coefficient decreases from .48 in the 1998 sample to .41 in the 1999 sample. In the following sections we will use a more sophisticated time series model to investigate the dynamic properties of the two return series.

Since both index return series are $I(1)$, the information on whether the series are cointegrated is required to properly model their interactions. The Johansen (1991) procedure is used to test for cointegration and the results are reported in table 3 . According to the trace and maximum eigenvalue statistics, the null hypothesis of no 
TABLE 2. Descriptive Statistics of the Index Return Series

\begin{tabular}{lrr}
\hline & DAX & DJI \\
\hline A. In 1998 & & \\
Mean & .05 & .06 \\
Median & -.01 & .11 \\
Maximum & 5.89 & 4.86 \\
Minimum & -6.44 & -6.57 \\
Std. Dev. & 1.85 & 1.27 \\
Correlation & .48 & \\
& & \\
B. In 1999 & & .07 \\
Mean & .1 & -.01 \\
Median & .25 & 2.79 \\
Maximum & 5.19 & -2.79 \\
Minimum & -5.29 & 1.02 \\
Std. Dev. & 1.35 & \\
Correlation & .41 &
\end{tabular}

Note: Panels A and B report the descriptive statistics for the first log differences of the DAX and DJI indexes.

TABLE 3. Cointegration Test Results

\begin{tabular}{|c|c|c|c|c|c|c|}
\hline & \multicolumn{2}{|c|}{ Eigenvalue } & \multicolumn{2}{|c|}{ Maximum Eigenvalue } & \multicolumn{2}{|c|}{ Trace } \\
\hline & 1998 & 1999 & 1998 & 1999 & 1998 & 1999 \\
\hline$r=0$ & .02 & .03 & 6.22 & 7.82 & 9.91 & 8.36 \\
\hline$r \leq 1$ & .01 & .0 & 3.68 & .53 & 3.68 & .53 \\
\hline
\end{tabular}

Note: The maximum eigenvalue and trace statistics were computed for the bivariate system consisting of the DAX and DJI indexes. All statistics are not significant according to the finite sample critical values (Cheung and Lai, 1993). Two lags were selected as the optimal lag structure by the Akaike information criterion.

cointegration is not rejected in the 1998 and 1999 samples. The stock markets under consideration do not experience common permanent shocks that drive their long-term swings and, thus, do not share a common long-run trend. The no-cointegration result is consistent with the findings reported in, for example, Richards (1995). 

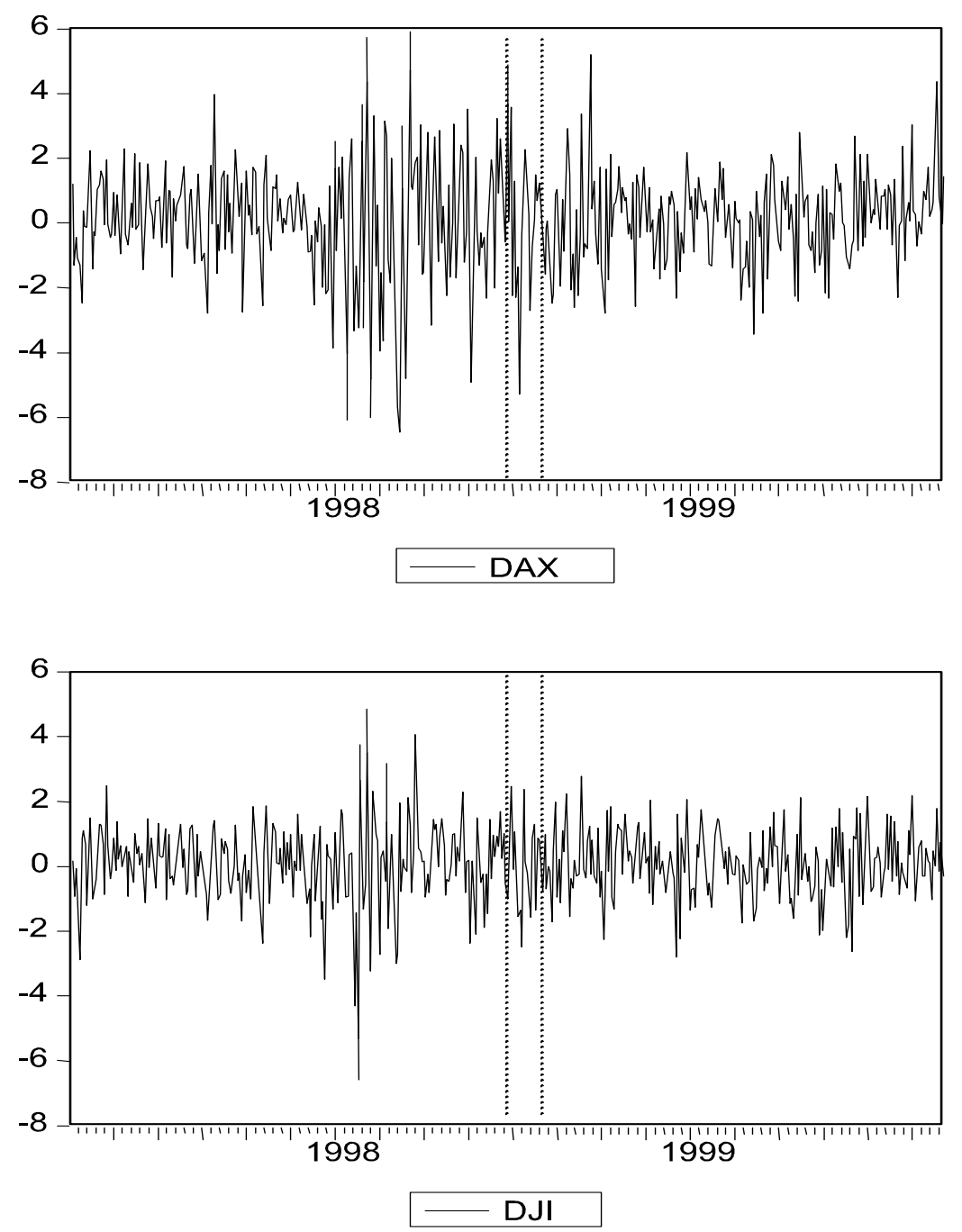

Figure 3.- The DAX and DJI indexes in first log differences, $1 / 2 / 1998$ to $12 / 30 / 1999$

\section{Univariate Dynamics}

In this section, the class of GARCH models (Engle, 1982; Bollerslev, 1986) is employed to jointly estimate the conditional mean and 
conditional variance of the individual equity index return series. We started with an MA(1)-GARCH-M model which is found to provide a good description of equity price dynamics (Bollerslev, Chou and Kroner, 1992). The model is given by

$$
\begin{gathered}
R_{t}=c+\phi_{1} h_{t}+u_{t}+\phi_{2} u_{t-1}, \\
h_{t}=\omega+\sum_{i=1}^{k} \varphi_{i} h_{t-i}+\varphi_{2} u_{t-1}^{2},
\end{gathered}
$$

and

$$
u_{t \mid t-1} \sim N\left(0, h_{i}\right)
$$

where $R_{t}$ is the return series, $u_{t}$ is the unexpected return, $h_{t}$ is the conditional variance, and $k$ is the maximum lag considered. Since equation 2 does not generate good diagnostic statistics for all the cases and not all the coefficients are significant, we dropped the insignificant variables from the regression and used the diagnostic statistic to determine the parsimonious models for individual cases. In some cases, an insignificant coefficient is retained to generate satisfactory diagnostic statistics. The estimation results are presented in table 4 . For the four cases, the $Q$-statistics computed from the standardized residuals and their squares are insignificant, indicating the selected models provide a reasonable description of the equity return dynamics.

The DAX return series displays different temporal dynamics before and after the introduction of the Euro (table 4A). In the 1998 sample, there is some dependence in the conditional mean dynamics and considerable persistence in conditional variances. In the 1999 sample, however, the moving average term is insignificant and the conditional variance parameter is small and marginally significant. The coefficient estimates also indicate that the unconditional variability of DAX return is higher in 1998 than in 1999, a result that is consistent with those in table 2. Thus, the DAX return series appears to have a lower level of persistence and smaller variation after the introduction of Euro.

The conditional variance dynamics of the DJI return series is quite complex in the 1998 sample (table 4B). During 1999, the conditional variance displays a simpler structure and lower level of persistence. The unconditional volatility implied by the coefficient estimates is also lower in the later sample period. Apparently, the decline in persistence and 
TABLE 4. GARCH Models for the Equity Index Return Series

\begin{tabular}{|c|c|c|c|c|c|}
\hline & Variables & & Sample & & Sample \\
\hline A. GARCH M & dels for th & X Retu & eries & & \\
\hline Mean & $c$ & .27 & $(.08)$ & .14 & $(.08)$ \\
\hline & $u_{t-1}$ & .1 & $(.04)$ & & \\
\hline Variance & $\omega$ & .93 & $(.24)$ & 1.66 & (.16) \\
\hline & $u_{t-1}^{2}$ & .4 & (.09) & 0 & (0) \\
\hline & $u_{t-2}^{2}$ & .45 & (.13) & .09 & $(.06)$ \\
\hline Residual tests & $Q$ & 1.9 & (5) & 8.53 & (5) \\
\hline & & 2.17 & (10) & 10 & (10) \\
\hline & $Q^{2}$ & 8.85 & (5) & 6.8 & (5) \\
\hline & & 13.4 & (10) & 8.79 & (10) \\
\hline Log-Likelihood & & -4 & & & \\
\hline B. GARCH M & dels for th & Return & & & \\
\hline Mean & $c$ & .15 & $(.07)$ & .08 & $(.06)$ \\
\hline & $u_{t-1}$ & -.05 & $(0.05)$ & & \\
\hline Variance & $\omega$ & .64 & $(.15)$ & .87 & $(.11)$ \\
\hline & $u_{t-1}^{2}$ & .16 & (.11) & .02 & $(.06)$ \\
\hline & $u_{t-2}^{2}$ & .16 & $(.04)$ & .12 & (.1) \\
\hline & $u_{t-3}^{2}$ & 0 & (0) & & \\
\hline & $u_{t-4}^{2}$ & .28 & $(.08)$ & & \\
\hline Residual tests & $Q$ & 5.12 & (5) & 7.68 & (5) \\
\hline & & 9.16 & (10) & 9.41 & (10) \\
\hline & $Q^{2}$ & 6.07 & (5) & 7.68 & (5) \\
\hline & & & (10) & 9.9 & (10) \\
\hline Log-Likelihood & & -3 & & & \\
\hline
\end{tabular}

Note: The results of fitting GARCH models to the DAX (Panel A) and DJI (Panel B) return series are reported. Heteroskedasticity consistent standard errors according to Bollerslev and Wooldridge (1992) are presented in parentheses next to the estimates. $Q$ and $Q^{2}$ are the $Q$-statistics based on the first five/ten autocorrelation coefficients calculated from the standardized residuals and $t$.

variability during 1999 is not unique to the DAX series.

However, from 1998 to 1999 , the variance reduction in the DAX series is much larger than that in the DJI series. In fact, when we test 
whether the reduction in the conditional variance variability is the same for both indexes, we obtain a statistic of 5.28, which is significant. The hypothesis that the reduction in the unconditional variance is the same for both indexes is also rejected by the sample statistic of $4.76 .{ }^{3}$ Thus, measured by changes in either conditional or unconditional variances, the decline in the DAX return variability is significantly larger than the DJI one.

\section{Interactions between DAX and DJI Indexes}

One possible implication of the single European currency is the way the German equity market is linked to other major exchanges. To investigate such a possibility, we compare the association patterns of the DAX and DJI return series before and after the introduction of the Euro. Given the GARCH estimation reported in the previous section, the Lagrange multiplier procedure of Cheung and $\mathrm{Ng}$ (1996) can be conveniently used to uncover the correlation patterns. In essence, the Cheung and $\mathrm{Ng}$ procedure employs the estimated standardized residuals and their squares to test whether there is any evidence of Granger causality in the conditional mean and conditional variance equations. Under the null hypothesis of no causality, the cross-correlation coefficients of the standardized residuals and their squares, computed from two series, are zeros. Table 5 reports the sample cross-correlation coefficients based on the residuals from models reported in table 4.

In table 5, the 'lag $k$ ' refers to the number of periods that the DAX index lags the DJI index. A lead is indicated by a negative lag. During each trading day, the German and the U.S. markets share a few common trading hours and the former closes before the latter. Thus, a significant correlation at lag 0 may reflect the presence of common news moving both markets or can be interpreted as the DAX index causing changes in the DJI index. The sample cross-correlation coefficients indicate causal interactions in both the 1998 and 1999

3. The statistic is given by $F=S_{D J I}^{2} / S_{D A X}^{2}$, which has an $F$-distribution with $(N-1$, $N-1$ ) degrees of freedom under the null hypothesis of equal variances and $S_{k}^{2}$ is the variance of series $k$. 
TABLE 5. Sample Cross-correlations of the Standardized Residuals from Models in Table 4

\begin{tabular}{|c|c|c|c|c|}
\hline \multirow[b]{2}{*}{$\operatorname{Lag} k$} & \multicolumn{2}{|c|}{1998} & \multicolumn{2}{|c|}{1999} \\
\hline & Levels & Squares & Levels & Squares \\
\hline-5 & -.046 & .071 & .061 & -.024 \\
\hline-4 & .084 & $.176^{*}$ & -.034 & -.007 \\
\hline-3 & -.044 & -.024 & -.029 & .04 \\
\hline-2 & -.036 & -.066 & -.115 & -.115 \\
\hline-1 & $.167 *$ & .078 & .029 & -.024 \\
\hline 0 & $.423 *$ & -.004 & $.414 *$ & $.215^{*}$ \\
\hline 1 & $.243 *$ & .028 & $.299 *$ & .014 \\
\hline 2 & -.037 & -.091 & $.12^{*}$ & -.061 \\
\hline 3 & .069 & .05 & .013 & -.077 \\
\hline 4 & -.038 & .079 & -.02 & -.017 \\
\hline 5 & -.011 & -.001 & .019 & $.217 *$ \\
\hline
\end{tabular}

Note: Table 5 reports the sample cross-correlations between the DAX stock index and the DJI index lagged $k$ times. A lead is denoted by a negative lag. Standardized residuals and their squares from the models in Table 4 are used to construct the sample cross-correlation statistics. Significance is indicated by “*”.

samples. ${ }^{4}$ Specifically, there is strong evidence that the return series interact with each other. The lead-lag relationship across the conditional variances, however, is rather weak. The correlation patterns in table 5 provide some useful information to further investigate the effect of one equity return series on the other.

The specification used to incorporate the interactions between equity return series is given by

$$
\begin{gathered}
R_{t}=c+\phi_{1} h_{t}+\sum_{i=1}^{k} \lambda_{i} R_{t-i}^{*}+u_{t}+\phi_{2} u_{t-1}, \\
h_{t}=\omega+\sum_{i=1}^{l} \varphi_{i} h_{t-i}+\sum_{i=1}^{m} \varsigma_{i} R_{t-i}^{2}+\varphi_{2} u_{t-1}^{2} .
\end{gathered}
$$

4. During crisis periods, conditional correlations tend to increase with conditional market volatilities. The Cheung and $\mathrm{Ng}$ procedure is based on unconditional correlation estimates and, thus, does not provide information on interactions between conditional moments. 
TABLE 6. Augmented GARCH Models for the Equity Index Return Series

\begin{tabular}{|c|c|c|c|c|c|}
\hline & Variables & 195 & ample & & ample \\
\hline A. Augmented & GARCH N & s for the & X Return & & \\
\hline Mean & $c$ & .2 & $(.08)$ & .09 & $(.08)$ \\
\hline & & .05 & $(.04)$ & & \\
\hline & & .38 & $(.08)$ & .4 & $(.08)$ \\
\hline & & .12 & $(.07)$ & & \\
\hline Variance & $\omega$ & .87 & $(.23)$ & 1.45 & $(.14)$ \\
\hline & & .39 & (.1) & 0 & (0) \\
\hline & & .44 & $(.13)$ & .11 & (.06) \\
\hline Residual tests & $Q$ & 7.62 & (5) & 9.99 & (5) \\
\hline & & 10.02 & (10) & 12.2 & (10) \\
\hline & $Q^{2}$ & 8.04 & (5) & 8.25 & (5) \\
\hline & & 10.04 & (10) & 9.78 & (10) \\
\hline Log-Likelihoo & & & & & \\
\hline B. Augmented & GARCH M & $s$ for the & I Return S & & \\
\hline Mean & $c$ & .09 & $(.05)$ & .04 & $(.06)$ \\
\hline & & -.07 & $(.04)$ & & \\
\hline & & .38 & $(.02)$ & .31 & $(.04)$ \\
\hline Variance & $\omega$ & .4 & $(.11)$ & .74 & (.12) \\
\hline & & .07 & $(.05)$ & .05 & $(.08)$ \\
\hline & & .48 & (.1) & .08 & $(.09)$ \\
\hline & & .01 & $(.07)$ & & \\
\hline & & .14 & $(.08)$ & & \\
\hline Residual tests & $Q$ & 7.96 & (5) & 9.61 & (5) \\
\hline & & 12.3 & (10) & 11.0 & (10) \\
\hline & $Q^{2}$ & 9.83 & (5) & 7.91 & (5) \\
\hline & & 11.7 & (10) & 9.23 & (10) \\
\hline Log-Likelihoo & & & & & \\
\hline
\end{tabular}

Note: The results of fitting augmented GARCH models (see Equation 3 and the related discussion) to the DAX (Panel A) and DJI (Panel B) return series are reported. Heteroskedasticity consistent standard errors according to Bollerslev and Wooldridge (1992) are presented in parentheses next to the estimates. $Q$ and $Q^{2}$ are the $Q$-statistics based on the first five/ten autocorrelation coefficients calculated from the standardized residuals and their squares, respectively. These $Q-$ statistics are not significant. 
Given equation 2, the effects of the "foreign" market are captured by $R_{t}^{*}$ and $R_{t}^{* 2}$, which are the return and squared return variables of the "foreign" equity series. Since the null hypothesis of the Cheung and $\mathrm{Ng}$ procedure is that the two series are independent, the presence of causality in mean may lead to spurious evidence of causality in variance and vice versa. Thus, in addition to the causality patterns in table 5, information on the significance of coefficients and diagnostic statistics is used to determine the final specification for the augmented model 3. The estimation results are reported in table 6 .

The results in table 6 reveal no evidence of causality in variance. That is, movements in the conditional variances of the two equity return series do not affect each other. The indication of causality in variance in table 5, thus, is likely to be spurious and induced by causality in the mean. For the German DAX index, the lagged U.S. return variables are significant in both the 1998 and 1999 samples. The magnitude of the first lagged U.S. variable is very similar across the two samples. Compared with the 1998 sample, the DJI index seems to have a more persistent effect on the German index in the 1999 sample as the second lagged U.S. return variable is also significant. Nonetheless, the size of this coefficient is much smaller than the first lagged variable. For the U.S. DJI index, the effects of the German index only come through the contemporaneous term in both sample periods. The size of the German effect, as indicated by magnitude of the estimated coefficients, is quite comparable in the two periods. As noted above, the significance of the contemporaneous German return variable may be attributed to the presence of news that reach the German and U.S. markets during the overlapping trading hours. If it is the case, then the results should not be interpreted as evidence that the German market has an impact on the U.S. equity price movement.

The log-likelihood values suggest that the augmented models presented in table 6 describe the data dynamics better than the univariate models in table 4. For example, consider the DAX models, the log-likelihood ratio statistics are 19.6 (the 1998 sample) and 26.3 (the 1999 sample). The augmented models for the DJI index show an even larger increase in the log-likelihood. Further, all the sample crosscorrelations based on the models in table 6 are statistically insignificant (Table 7). These results suggest that the augmented models reasonably capture the dynamic interactions of the DAX and DJI return series. 
TABLE 7. Sample Cross-correlations of the Standardized Residuals from the Augmented Models in Table 6

\begin{tabular}{|c|c|c|c|c|}
\hline \multirow[b]{2}{*}{$\operatorname{Lag} k$} & \multicolumn{2}{|c|}{1998} & \multicolumn{2}{|c|}{1999} \\
\hline & Levels & Squares & Levels & Squares \\
\hline-5 & -.061 & .059 & .017 & .049 \\
\hline-4 & .05 & .141 & .02 & .071 \\
\hline-3 & -.079 & -.048 & -.054 & -.004 \\
\hline-2 & .062 & -.013 & -.127 & -.078 \\
\hline-1 & .037 & .018 & .015 & -.02 \\
\hline 0 & -.086 & -.048 & -.107 & .102 \\
\hline 1 & .033 & .004 & .015 & .019 \\
\hline 2 & -.028 & -.003 & .073 & .034 \\
\hline 3 & .001 & -.051 & .01 & .024 \\
\hline 4 & -.054 & .052 & .068 & -.069 \\
\hline 5 & -.005 & .11 & -.018 & .135 \\
\hline
\end{tabular}

Note: Table 7 reports the sample cross-correlations between the DAX stock index and the DJI index lagged $k$ times. A lead is denoted by a negative lag. Standardized residuals and their squares from the augmented models in Table 6 are used to construct the sample cross-correlation statistics. All the sample cross-correlation statistics are insignificant.

\section{Conclusions}

The recent introduction of the single European currency provides a unique opportunity to study the implication of exchange rate policy for equity price behavior. As a casual observation, the volatility of the Dollar/Euro exchange rate in 1999 is much lower than that of the Dollar/Mark rate in, for example, 1998. The reduction in exchange rate uncertainty can lead to reduction in equity market uncertainty (Krugman and Miller, 1993). Using data from German and U.S. equity markets, we find that both the DAX and DJI indexes display a decline in volatility and in the volatility persistence. Nonetheless, the volatility decrease in the DAX index is significantly larger than that in the DJI index. On the persistence of returns, the moving average component of the DAX return series disappears after the introduction of the Euro. The reduction in volatility and persistence is consistent with the reduced exchange rate volatility following the introduction of the Euro. 
The launch of the Euro, on the other hand, seems to have a limited impact on the linkage between the German and U.S. stock indexes. Apparently, the effect of the DJI index on the DAX index does not depend on the exchange rate regime. In both sample periods considered, the lagged U.S. return data help explain movements in the DAX index. It is also found that the contemporaneous German data provide incremental explanatory power to the U.S. equity return equation. However, such incremental explanatory power may be attributed to common news reaching the two markets during their overlapping trading hours.

Using the U.S. data as a control, we find some evidence on the effect of the single European currency on the German equity index. However, the exercise has not accounted for possible changes in the German macroeconomic policy before and after the introduction of the Euro. An interesting future research agenda is to investigate the effect of exchange rate regime choices conditioning on other macroeconomic policy variables.

\section{References}

Artis, M. J., and Taylor, M. P. 1994. The stabilizing effect of the ERM on Exchange rates and interest rates. IMF Staff Papers 41, 123-148.

Baxter, M., and Stockman, A. C. 1989. Business cycles and the exchange rate regime: Some international evidence. Journal of Monetary Economics 23: 377-400.

Berger, H.; de Haan, J.; and Sturm, J. E. 2000. An empirical investigation into exchange rate regime choice and exchange rate volatility. CESifo Working Paper 263, 2000.

Bodart V., and Reding, P. 1999. Exchange rate regime, volatility and international correlations on bond and stock markets. Journal of International Money and Finance 18: 133-151.

Bollerslev, T. 1986. Generalized autoregressive conditional heteroskedasticity. Journal of Econometrics 31: 307-327.

Bollerslev, T.; Chou, R. Y.; and Kroner, K. F. 1992. ARCH modeling in finance: A review of the theory and empirical evidence. Journal of Econometrics 52: 5-59.

Bollerslev, T., and Wooldridge, J. M. 1992. Quasi-maximum likelihood estimation and inference in dynamic models with time-varying covariances. Econometric Reviews 11: 143-72. 
Cheung, Y. W., and Lai, K. S. 1993. Finite sample sizes of Johansen's likelihood ratio tests for cointegration. Oxford Bulletin of Economics and Statistics 55: 313-328.

Cheung, Y. W., and Lai, K. S. 1995. Lag order and critical values for the augmented Dickey-Fuller test. Journal of Business \& Economic Statistics 13: 277-80.

Cheung Y. W. and $\mathrm{Ng}$, L. K. 1996. A causality-in-variance test and its application to financial market prices. Journal of Econometrics 73: 33-48.

Engle, R. F. 1982. Autoregressive conditional heteroskedasticity with estimates of the variance of U.K. inflation. Econometrica 50: 987-1008.

Flood, R. P., and Rose, A. K. 1995. Fixing exchange rates: A virtual quest for fundamentals. Journal of Monetary Economics 36: 3-37.

Frankel, J. A., and Mussa, M. L. 1980. The efficiency of the foreign exchange market and measures of turbulence. American Economic Association papers and proceedings 70: 374-381.

Johansen, S. 1991. Estimation and hypothesis testing of cointegration vectors in gaussian vector autoregressive models. Econometrica 59: 1551-1581.

Krugman P., and Miller, M. 1993. Why have a target zone. Carnegie Rochester Conference series on Public Policy 38: 279-314.

Marston, R. C. 1985. Stabilization policies in open economies. In: Jones, R. W., and Kenen, P. B.(Eds.), Handbook of international Economics 2: 859-916. Amsterdam: North Holland.

Melvin, M. 1985. The choice of an exchange rate regime and the macroeconomic stability. Journal of Money Credit and Banking 17: 467-78.

Richards, A. 1995. Co-movements in national stock market returns: Evidence of predictability, but not cointegration. Journal of Monetary Economics 36 (3): 631-654.

Rose A. K. 1995. After the deluge: Do fixed exchange rates allow inter-temporal volatility trade offs?. International Journal of Financial Economics 1: 4754. 